\title{
FUNCTIONAL OUTCOME OF DISPLACED MIDSHAFT FRACTURE OF CLAVICLE USING LCP RECONSTRUCTION PLATE 3.5
}

\author{
H. Shantikumar Singh ${ }^{1}$, O. Guneshwar Singh ${ }^{2}$, Nickson Maku ${ }^{3}$
}

${ }_{1}^{1}$ Assistant Professor, Department of Orthopaedics, J. N. Institute of Medical Sciences, Porompat, Imphal, Manipur, India.

${ }^{2}$ Associate Professor, Department of Orthopaedics, J. N. Institute of Medical Sciences, Porompat, Imphal, Manipur, India.

${ }_{3}^{3}$ Postgraduate Student, Department of Orthopaedics, J. N. Institute of Medical Sciences, Porompat, Imphal, Manipur, India.

\section{ABSTRACT}

\section{BACKGROUND}

Treatment of displaced mid-shaft clavicle fractures is still controversial. Biomechanical studies conducted by different authors indicate better functional outcome with surgical treatment. The aim of the present study is to evaluate the results of use of LCP reconstruction plate 3.5 .

\section{METHODS}

We retrospectively analysed the functional outcome of 52 cases of displaced midshaft fractures of clavicle treated by using LCP reconstruction plate 3.5 during the period July 2012-June 2017. In the present study, functional outcomes were assessed using Constant-Murley Score and DASH Questionnaire and the cases were followed up for a mean period of 5.6 months.

\section{RESULTS}

We achieved excellent and good results in all 52 patients being evaluated. The mean Constant-Murley score was 91.76 and DASH Questionnaire was 12.40. We had 2 cases of delayed union. There was no case of deep infection, vascular or nerve lesions.

\section{CONCLUSIONS}

Currently there are many surgical procedures for treatment of displaced midshaft clavicle fractures. Our experience with LCP reconstruction plate 3.5 has given excellent outcome and on the basis of our finding, we recommend the use of LCP reconstruction plate 3.5 for such fractures.

HOW TO CITE THIS ARTICLE: Singh HS, Singh OG, Maku N. Functional outcome of displaced midshaft fracture of clavicle using LCP reconstruction plate 3.5. J. Evolution Med. Dent. Sci. 2019;8(17):1362-1367, DOI: $10.14260 / \mathrm{jemds} / 2019 / 303$

\section{BACKGROUND}

The clavicle, also known as collar bone, connects upper limb to trunk and hence, it plays an important role in providing mobility and stability of upper limb. Clavicle has a double curve which is concave anteriorly at lateral end and convex anteriorly at medial end. The convex medial portion also gives protection to subclavian vessels and brachial plexus. The cross-sectional geometry at medial portion is tubular and changes to flat at lateral portion. This change in cross sectional geometry is maximum at the junction of middle third and lateral third and this may be the reason why fractures most commonly occur in this area. ${ }^{1}$ Again, the bone at the middle third being the junction of two opposite curves is thinner and weaker which may also be responsible for the increased frequency of fractures. ${ }^{2,3}$

Two to five percent of all adult fractures and ten to fifteen percent of all fractures in children affects clavicle.4,5 Clavicle lies beneath the skin and thin platysma muscle thus making it least protected bone by muscle or fat. ${ }^{6}$ The midshaft fractures are more likely to be displaced in comparison to fractures affecting medial and lateral third areas of the bone.

'Financial or Other Competing Interest': None.

Submission 08-03-2019, Peer Review 12-04-2019,

Acceptance 19-04-2019, Published 29-04-2019.

Corresponding Author:

Dr. O. Guneshwar Singh,

Associate Professor,

Department of Orthopaedics,

J. N. Institute of Medical Sciences,

Porompat, Imphal-795005, Manipur, India.

E-mail: singhguneshwar@ymail.com

DOI: $10.14260 /$ jemds $/ 2019 / 303$
The lateral end of the clavicle is fixed to the coracoid process by the coracoclavicular ligament, having the lateral trapezoid and medial conoid parts. The acromio-clavicular ligament controls horizontal stability whereas coracoclavicular ligaments controls vertical stability. The trapezius muscle attached to the dorsal aspect of the acromion and part of the deltoid muscle which is attached the lateral part clavicle act as dynamic stabilizers. They also prevent excessive upward migration of lateral end of clavicle after disruption of acromio-clavicular and coraco-clavicular ligaments. ${ }^{7}$ In children and young individuals clavicle fractures are due to moderate to high energy trauma such as sports related or motor vehicle accident but in elderly person fractures are usually due to lower energy fall. ${ }^{8}$

Numerous classification systems have been proposed by different authors, but the Edinburg classification proposed by Robinson CM (1998) has been adopted for classification of clavicle fractures in our study. Close treatment of displaced mid-third fractures are usually associated with poor outcome. ${ }^{9}$ Operative osteosynthesis had the potential to achieve early union and rapid return to function avoiding mal-union or non-union. As use of smooth intramedullary devices is associated with lack of compression at fracture site in addition to chances of pin migration, we decided to use 3.5 LCP reconstruction plate for operative fixation of such fractures. ${ }^{10}$

The aim of this study is to report the result of retrospective analysis of 52 cases of displaced midshaft clavicle fractures treated by using 3.5 LCP reconstruction plate over a period of 5 years. 


\section{METHODS}

This descriptive study 52 cases of displaced \& shortened fractures of the middle third of clavicle treated between July 2012 and June 2017 at Jawaharlal Nehru Institute of Medical Sciences, Imphal by using 3.5 LCP reconstruction plate were included in the retrospective study. All data were collected from the available medical records of the hospital. The fractures were classified according to Edinburgh classification described by Robinson CM. The fracture types were of type $2 \mathrm{~B}$ of the classification - 38 cases were of type 2 $\mathrm{B}_{1}$ and 14 cases were type type $2 \mathrm{~B}_{2}$.

All displaced fractures of the middle third of the clavicle in the age group of 18-60 years within 3 weeks of injury and not having serious medical illness were included in the study. Multi-trauma patients, patients having fracture in the same extremity, open fractures, fractures older than 3 weeks, patients with known history of drug/alcohol abuse were excluded from the study.

A total of forty patients attended emergency wherein twelve cases were from orthopaedic outpatient department. All patients were clinically and radiologically evaluated. Radiographic assessment includes anteroposterior (AP), $45^{\circ}$ upward projection or tangential, $45^{\circ}$ downward projection views of the clavicle as these views are helpful in assessing the displacement of the fracture. A chest $\mathrm{X}$ ray was included as the patient had to undergo operation under general anaesthesia (GA) and also to exclude haemothorax or pneumothorax. All routine blood investigations were done.

Operative procedure:- All cases were operated under GA. Patient was kept in supine position with slight tilting of the head end of the table to reduce bleeding during surgery. A sandbag was placed between the two scapulae to allow the shoulder girdle to fall backwards thus helping to restore length of clavicle and also increasing the exposure of clavicle. The head of the patient was kept at the foot end of the operating table for easy access of $\mathrm{C}$-arm (if required). The whole upper chest, shoulder, side of neck, arm and forearm were cleaned and draped.

A longitudinal incision centering over the fracture site was given over the superior aspect of the clavicle. The subcutaneous tissue along with platysma were incised together and mobilized. The fracture site was exposed, cleaned and reduced by using appropriate bone clamps and by manipulation of the arm. If the fracture is oblique or spiral or if there is a large butterfly fragment, an interfragmentary lag or cortical screw was applied. Then, a well contoured 3.5 LCP reconstruction plate was placed extraperiosteally along the superior aspect of the clavicle using three screws in each fragment - initially two cortical screws in each fragment followed by one locking head screw in each fragment. Depth gauge measured the exact length of the screw. As far as practicable bicortical purchase was aimed. Wound was sutured in layers (myofascial followed by subcuticular) after thorough haemostatis without putting any drain. Incision site was kept clean and dry. Injectable antibiotics were given for 3 days followed by oral antibiotic for one week. Stitches were removed at $2^{\text {nd }}$ week.

Operative limb was kept in a sling for $2-3$ weeks. During the first 3 weeks, light activities were allowed. Active exercise of hand, wrist and elbow were undertaken from the next day of surgery to prevent contractures and peripheral oedema. Isometric exercises of deltoid muscle were also prescribed so as to preserve tone of the muscles. Range of movement (ROM) and muscle strengthening exercises were intensified once there is clinical evidence of union as evidenced from absence of local tenderness at the original fracture site and no pain at shoulder girdle on motion. Load bearing and full activities were delayed until there are signs of clinical and radiological union.

Rehabilitation protocol adopted:

- First 2 weeks - Arm sling.

- $\quad$ First 3 weeks - Pendulum motion.

- 6 weeks - Active abduction and flexion up to horizontal plane.

- After 6 weeks - Full active range of motion at shoulder joint.

- $\quad$ After 3 months - Full activities permitted.

Clinical and radiological assessment was done for each and every patient at the end of $1^{\text {st }}$ month, $2^{\text {nd }}$ month, 3 rd month and last available follow up after the operation and at the end of $6^{\text {th }}$ month $\& 9^{\text {th }}$ month for the two cases of delayed union. Average follow up was 5.6 months (range 4-9 months). Functional outcome was assessed using Constant-Murley shoulder outcome score at the end of each follow up. Clinical evaluation for all patients were done using Constant-Murley Score. There are 100 points in the scoring system - 35 subjective and 65 objectives. Pain and ADL were answered by the patient and ROM and strength were also evaluated. Radiological evaluation was done as per DASH (Disabilities of the Arm, Shoulder and Hand) Questionnaire. The DASH has four sections A-D. A and B are considered the function/symptom portion of the test comprising of 30 items that are marked from 1 (No difficulty) to 5 (unable). C \& D are optional components and contain 4 questions each with maximum score of 20 . The score range for quick DASH is zero to 100 with higher values indicative of more disability.

\section{RESULTS}

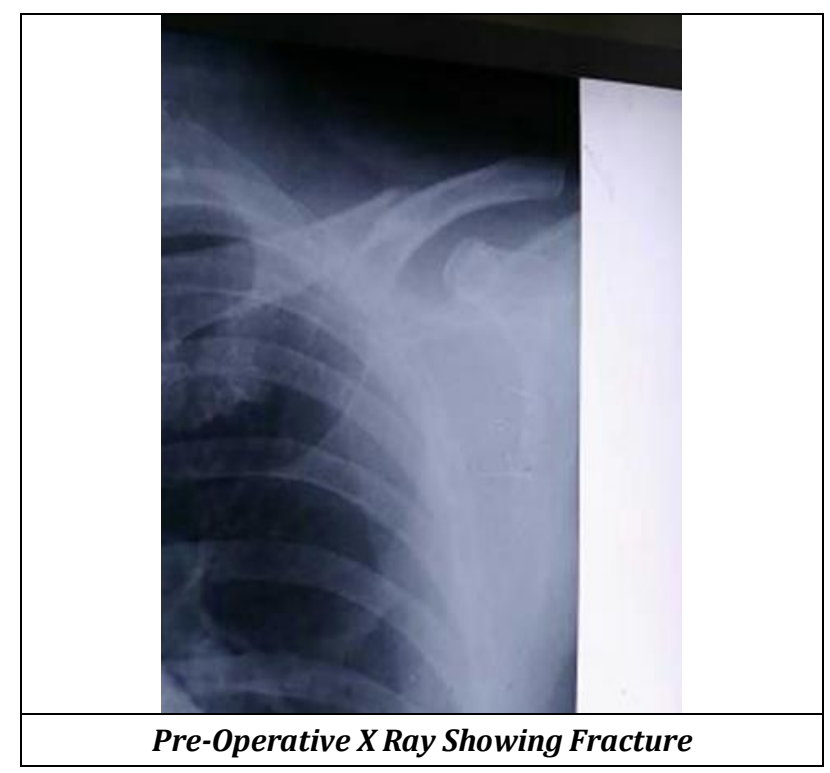

The retrospective study design analysis was done in 52 cases for whose follow up was available. There were 38 male and 14 female patients. In 24 cases the right clavicle was involved and in the remaining 28 cases left side was involved. 
Road traffic accident was the cause in 35 cases, sports related injuries in 7 cases, accident at workplaces in 6 cases and domestic accident in the remaining 4 cases. The youngest patient was 18 years and oldest 60 years. Mean age was 35 years (range 18 - 60 years). 50 out of 52 cases studied united at the end of 3 months. Average healing time was 9.5 weeks (range 8-12 weeks). There were two cases of delayed union. Out of the two cases of delayed union one united at 5 months and second one united at $8^{\text {th }}$ month. There were two cases of neuropraxia on ulnar border of hand which resolved by $8^{\text {th }}$ week. There were no cases of non-union and deep wound infection. There were 3 cases of superficial wound infection which resolved on continued wound care and continuation of oral antibiotics for one more week.

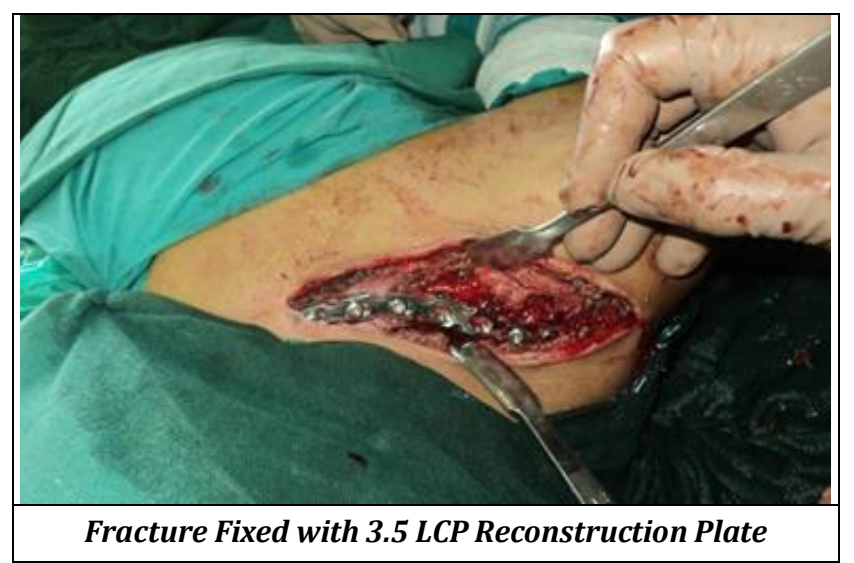

The average follow-up was 5.6 months (range 4-9 months). 38 (73.8\%) patients had complete range of motion at shoulder joint by the end of 3 months and of the remaining 14

$27.12 \%$ ) patients had some restriction of the range of shoulder movement which eventually recovered fully on further physiotherapy over a period of one to two months except the 2 cases of delayed union. Intensive physiotherapy was not done for these two cases of delayed union. Out of these two cases, one regained almost full range of motion by $6^{\text {th }}$ month and second one by $9^{\text {th }}$ month.

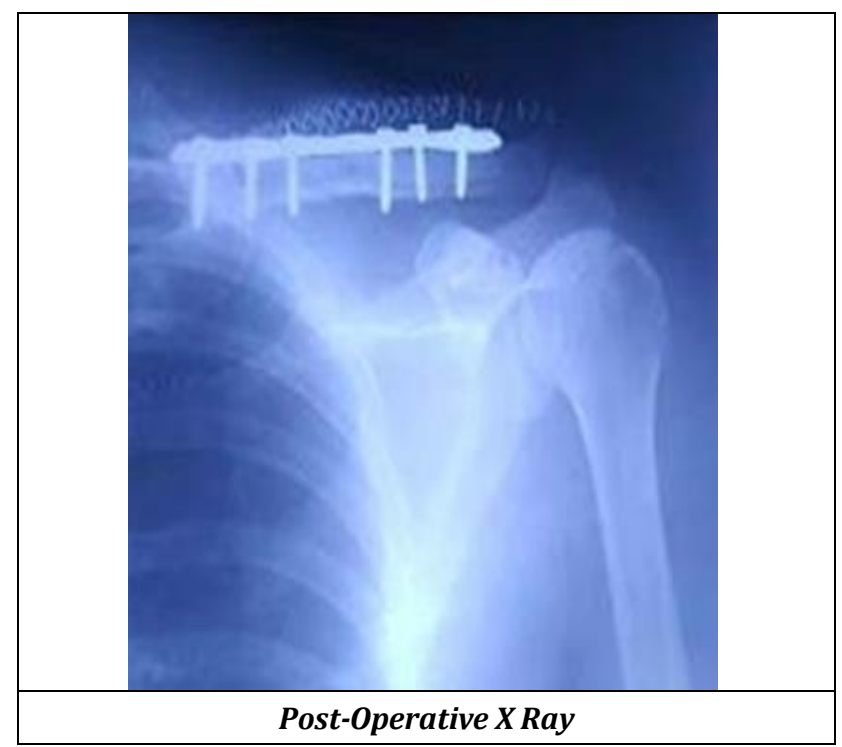

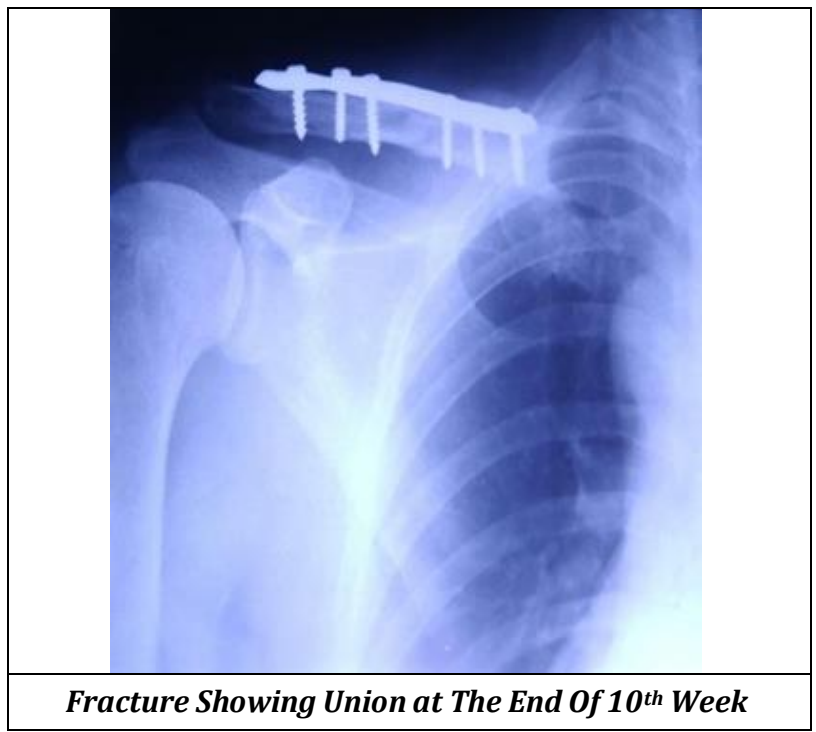

Most of the patients resumed their activities of daily living on an average of 5 to 7 weeks from the date of injury. They resumed their original work at an average of 7 weeks (range 6-8 weeks) for those sedentary workers. Those who did strenuous activities and sportsperson resumed their usual activities by $11^{\text {th }}$ week (range $10-12^{\text {th }}$ week).

The functional outcome was assessed by using Constant Murley Score at the end of follow up. We obtained excellent clinical result with a mean Constant Murley Score of $91.76 \pm$ 5.41 (range 79 - 100 and DASH score of 12.40 (range 227.5).

Plate was removed after fracture consolidation in 7 patients $(13.5 \%)$. Reason for plate removal was prominence of plate and discomfort in 5 patients and pain in 2 patients. None of the patients whose plate were removed had any report of refracture up to 6 months after removal of plate (last follow up).

There was one case of implant loosening. The patient was immobilized using a sling until fracture consolidation and then the plate was removed.

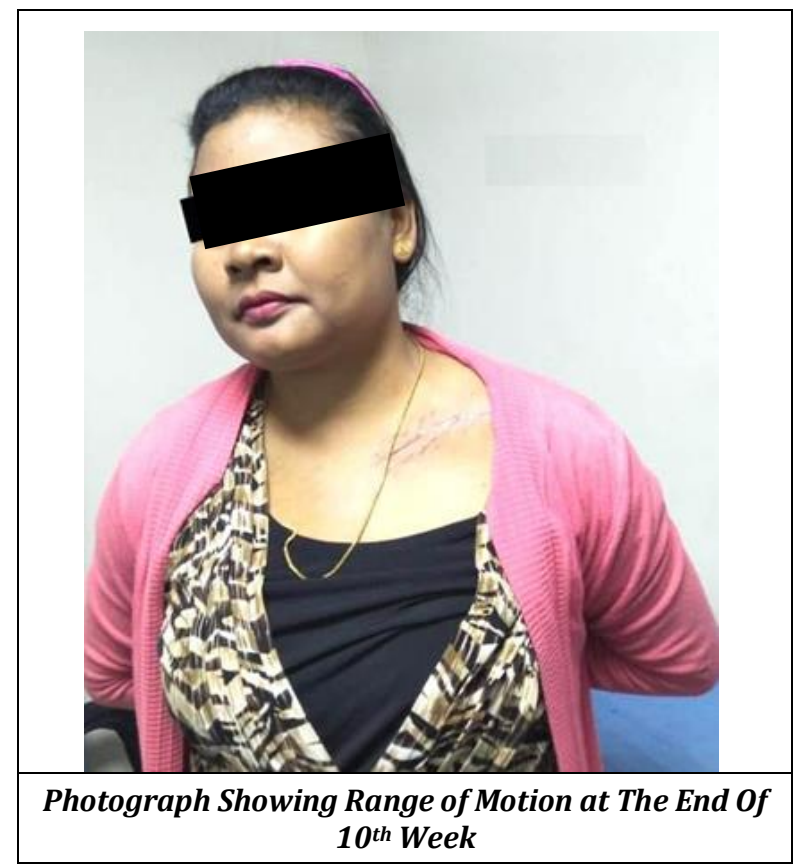



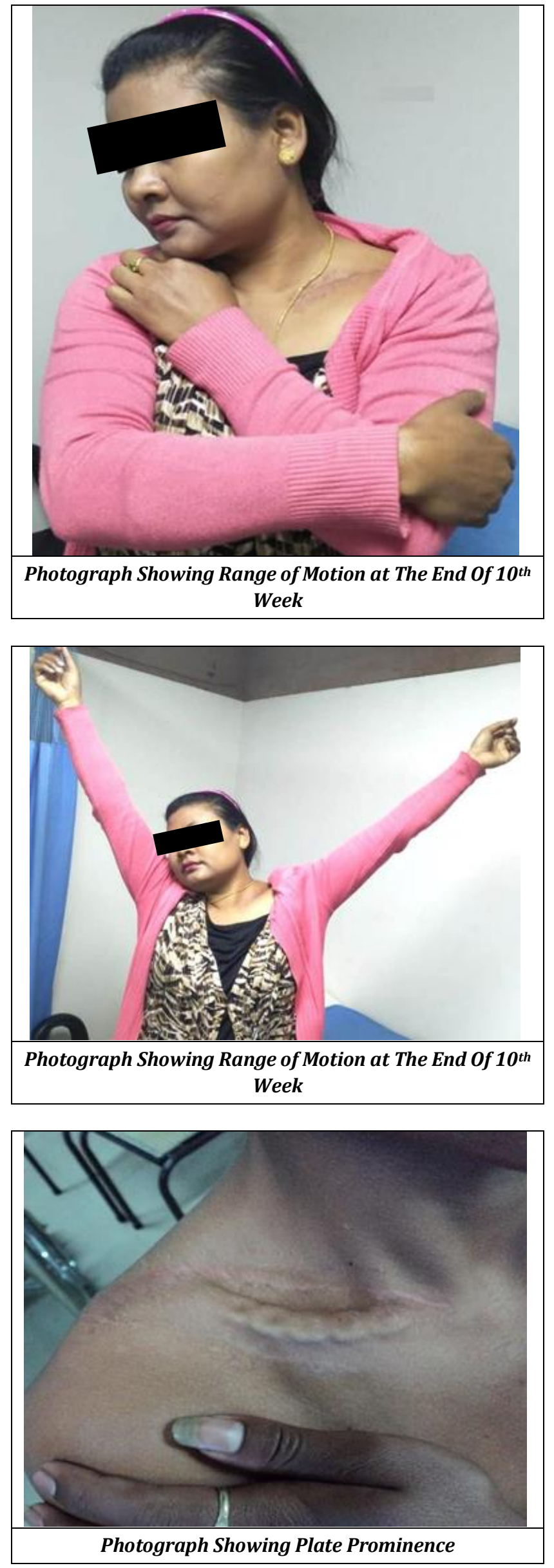

\begin{tabular}{|c|c|c|c|}
\hline Sl. No. & Cause of Fracture & No & Percentage \\
\hline 1 & RTA & 35 & 67.3 \\
\hline 2 & Sports Related Injuries & 8 & 15.38 \\
\hline 3 & Accident at Workplace & 5 & 9.62 \\
\hline 4 & Domestic Accident & 4 & 7.69 \\
\hline & Total & 52 & $100 \%$ \\
\hline \multicolumn{4}{|c|}{ Table I. Showing Causes of Fracture } \\
\hline
\end{tabular}

\begin{tabular}{|l|c|c|}
\hline Age Group & Number & Percentage \\
\hline 18-30 Years & 25 & 48.07 \\
\hline 31-45 Years & 22 & 42.31 \\
\hline 46-60 Years & 5 & 9.62 \\
\hline \multicolumn{2}{|l}{ Table II. Showing Age Distribution of Fracture } \\
\hline
\end{tabular}

\begin{tabular}{|c|c|c|c|}
\hline Sl. No. & Complication & Number & Percentage \\
\hline 1 & Superficial Infection & 3 & 5.77 \\
\hline 2 & Delayed Union & 2 & 3.85 \\
\hline 3 & Neuropraxia & 2 & 3.85 \\
\hline 4 & Incisional Numbness & 3 & 5.77 \\
\hline 5 & Hypertrophic Scar & 1 & 1.92 \\
\hline 6 & Implant Loosening & 1 & 1.92 \\
\hline 7 & Non-Union & Nil & - \\
\hline 8 & Vascular Lesion & Nil & - \\
\hline \multicolumn{4}{|c|}{ Table III. Showing Complications } \\
\hline
\end{tabular}

\begin{tabular}{|c|c|}
\hline Parameter (At the last Follow Up) & Total Score \\
\hline $\begin{array}{c}\text { Constant-Murley Score (0-100) } \\
\text { Mean }\end{array}$ & $91.76( \pm 5.41)$ \\
Range & $79-100$ \\
\hline Mean & $12.40( \pm 7.3)$ \\
Range & $2-27.5$ \\
\hline \multicolumn{2}{|c|}{ Raick DASH Score (100-0) IV. Showing Constant-Murley Score and Quick DASH } \\
\hline
\end{tabular}

\section{DISCUSSION}

A total of 52 cases of displaced fracture of middle third of clavicle treated by using 3.5 LCP reconstruction plate were selected for the study. Current opinion regarding the treatment of displaced clavicle fractures is in favour of operative intervention as compared to conservative treatment as it reduces chances of non-union and have better functional outcome. 10

A survey conducted on several Orthopaedic surgeons has found that for displaced midshaft fractures operative treatment is preferred by most surgeons ${ }^{11}$. If perfect shoulder movement is to be achieve early surgery is required. ${ }^{12}$ Timely surgical management of displaced clavicle fractures helps in early return to work and better patient satisfaction. ${ }^{13}$ Open reduction and internal fixation of displaced clavicle fractures can be performed safely even in children with good results. ${ }^{14}$

Pearson et $\mathrm{al}^{15}$ have reported that average age of patients sustaining a clavicle fracture is 33 years, but the mean age in our study is 35 years. 25 patients $(48.07 \%)$ belong to the age group of 18 - 30 years followed by 22 patients $(42.31 \%)$ in the age group of $31-45$ years. There were $73 \%$ male in our study but Postacchini et al ${ }^{16}$ reported that $68 \%$ are male in their study. Postacchini et al 16 described left side was involved in $61 \%$ of cases but in our study left side was affected in only $54 \%$ of the cases. 
The mean time of fracture healing in our study is 9.5 weeks. Cesari Faldini et al reported an average healing time of 9 weeks. Several other studies reported healing time varying from as early to 8.8 weeks to $14-16$ weeks (MCKee et al). The determining factor might be degree of comminution at fracture site and technique of soft tissue handling during surgery. Average follow up in our study is 5.6 months (range 4-9 months)

The main cause of fracture was RTA (67.30\%) followed by sports related injuries (15.38\%). But similar studies by Maximiliano et al sports related trauma in $39.7 \%$ followed by RTA in $26.5 \%$.

Whenever there is comminution or in osteoporotic bone 3.5 LCP reconstruction plate is still good as the construct is stiff enough and also gives angular stability. We had two cases of delayed union. In one case, severe comminution and disruption of soft tissue during surgery might be the reason and in the second case there was a comminuted butterfly fragment. We fixed the main butterfly fragment with 2.7 cortical screw to one fragment. In such case MIPPO (Minimally invasive plate osteosynthesis) might be the better option as the fracture site is not disturbed due to indirect reduction.

We adopted superior plate placement as it is the tension side giving more stability and disadvantage is prominent hardware due to thin soft tissue coverage. Therefore, meticulous handling of soft tissue is extremely essential. When there is inferior cortical comminution, superior plating is thought to be a better option. We considered stability to be more important than cosmesis, for which anterio-inferior plating is better due to chance of less hardware irritation. Proper contouring of the plate and using standard cortex screws to bring the plate close to the bone before applying LHS (Locking head screw), helps in reducing plate prominence. But in very tall and heavy patients, anatomical clavicle LCP will be better as it is stronger and prevents deformation of the plate. To avoid neurovascular injury preoperative measurement of clavicle size and adjustment of drill bit length and use of correct length of screw by accurate measurement of screw length by depth gauge is very important. Plate removal was done after fracture consolidation due to plate prominence and discomfort in 5 patients and pain in 2 patients. Superior plate placement was chosen during the study as anterior placement is usually thought to be associated with more chance of injury to brachial plexus.

The analysis of functional outcome has shown excellent mean Constant - Murley Score of 91.76 and DASH score of 12.40. In addition, mean period of fracture consolidation was 9.5 weeks and return to their original work at 7 weeks for sedentary workers whereas strenuous activities or sporting activities were resumed at $11^{\text {th }}$ week. We did not find any significant difference in functional outcome between the two sub types of 2 B of Robinson classification.

LCP reconstruction plate has the advantage of stronger fixation due to locking of the screw in the plate hole and because of its limited contact blood supply to bone is also preserved 17,18 . While using conventional plate and screws stability at fracture site is due to friction of the plate to the bone cortex and hence screws need to be fixed to both cortices. But, when LCP is used force is transferred from the bone through the threaded plate hole to the plate as the screw head is locked in the threaded plate hole. Hence, intimate contact of the plate to the cortical bone is not required thereby helping in preservation of blood supply. Moreover, locking of the screw head to the plate helps in preventing screw loosening ${ }^{18}$. Another advantage of LCP is that the chances of injury to brachial plexus or subclavian artery is also less as it is not necessary to have bicortical purchase and periosteal stripping is also minimized thereby helping in faster bone union ${ }^{19}$. Periosteal stripping can be minimized by using self-tapping screws. Operating time can also be reduced as accurate plate contouring is not necessary while using LCPs.

\section{CONCLUSIONS}

Midshaft fracture of clavicle usually occurs in young and active persons. LCP reconstruction plate 3.5 has all the advantages of being a reconstruction plate. The locking head screw (LHS) also imparts angular stability. But accurate contouring of the plate is essential to reduce plate prominence.

Ideal candidate should be a healthy young person presenting with comminuted, displaced and shortened fracture of the middle third of the clavicle. Midshaft clavicle fractures are more commonly caused by RTA. Age group 1830 years was the most commonly affected group in the study. Mean age was 35 years. Males are more commonly affected than females. Open reduction and internal fixation are essential for restoring anatomy as well as for articular congruence. It also reduces chances of non-union due to interposition of soft tissue at fracture site. Functional outcomes are better with reconstruction locking compression plate. The success of surgery also depends on proper patient selection, careful assessment of fracture pattern, meticulous surgical technique, judicious internal fixation, careful postoperative care and monitoring and early rehabilitation. So, final functional result of middle third fractures depends not only on accurate reduction but also on meticulous handling of soft tissues and early rehabilitation. Therefore, operative intervention of displaced midshaft clavicle fractures have faster union, early return to activity and good functional outcome.

\section{REFERENCES}

[1] Ljunggren AE. Clavicular function. Acta Orthop Scand 1979;50(3):261-8.

[2] Rowe CR. An atlas of anatomy and treatment of midclavicular fractures. Clin Orthop Relat Res 1968;58:29-42.

[3] Robinson CM. Fractures of the clavicle in the adult. Epidemiology and classification. J Bone Joint Surg $\mathrm{Br}$ 1998;80(3):476-84.

[4] Neer CS 2nd. Fractures of the distal third of the clavicle. Clin Orthop Relat Res 1968;58:43-50.

[5] Nordqvist A, Peterson C, Redlun-Johnell I. The natural course of lateral clavicle fracture. 15 (11-21) year follow-up of 110 cases. Acta Orthop Scand 1993;64(1):87-91.

[6] Preston CF, Egol KA. Midshaft clavicle fractures in adults. Bull NYU Hosp Jt Dis 2009;67(1):52-7.

[7] Toogood P, Horst P, Samagh S, et al. Clavicle fractures: a review of the literature and update on treatment. Phys Sportsmed 2011;39(3):142-50. 
[8] Browner BD, Jupiter JB. Skeletal trauma. $3^{\text {rd }}$ edn. Philadelphia, PA: WB Saunders 2003.

[9] Hill JM, McGuire MH, Crosby LA. Closed treatment of displaced middle third fracture of the clavicle gives poor results. J Bone Joint Surg 1997;79(4):537-9.

[10] Robinson CM, Goudie EB, Murray IR, et al. Open reduction and plate fixation versus non-operative treatment for displaced midshaft clavicular fractures: a multicenter, randomized, controlled trial. J Bone Joint Surg Am 2013;95(17):1576-84.

[11] Brin YS, Palmanovich E, Dolev E, et al. Displaced midshaft clavicular fractures: is conservative treatment still preferred? Isr Med Assoc J 2014;16(12):748-52.

[12] George DM, McKay BP, Jaarsma RL. The long-term outcome of displaced mid-third clavicle fractures on scapular and shoulder function: variations between immediate surgery, delayed surgery and nonsurgical management. J Shoulder Elbow Surg 2015;24(5):66976.

[13] Alshameeri ZA, Katam K, Alsamaq $M$, et al. The outcome of surgical fixation of mid shaft clavicle fractures: looking at patient satisfaction and comparing surgical approaches. Int J Shoulder Surg 2012;6(3):76-81.
[14] Mehlman CT, Yihua G, Bochang C, et al. Operative treatment of completely displaced clavicle shaft fractures in children. J Pediatr Orthop 2009;29(8):851-5.

[15] Pearson AM, Tosteson AN, Koval KJ, et al. Is surgery for displaced, midshaft clavicle fractures in adults cost-effective? Results based on a multicenter randomized, controlled trial. J Orthop Trauma 2010;24(7):426-33.

[16] Postacchini F, Gumina S, De Santis P, et al. Epidemiology of clavicle fractures. J Shoulder Elbow Surg 2002;11(5):452-6.

[17] Perren SM. Evolution and rationale of locked internal fixator technology: introductory remarks. Injury 2001;32 Suppl 2:B3-9.

[18] Gautier E, Sommer C. Guidelines for the clinical application of the LCP. Injury 2003;34 Suppl 2:B63-76.

[19] Wagner M. General principles for the clinical use of the LCP. Injury 2003;34 Suppl 2:B31-42. 